DOI: $10.21767 / 2472-1158.100023$

\title{
Guest Editorial: Breast Cancer Epigenetics in the Era of Precision Medicine
}

\section{Athena Starlard Davenport*}

Assistant Professor, Department of Genetics, Genomics and Informatics, University of Tennessee Health Science Center, United States

*Corresponding author: Athena Starlard Davenport, PhD, Assistant Professor, Department of Genetics, Genomics and Informatics, University of Tennessee Health Science Center, United States, Tel: + 901-448-3085; E-mail: astarlar@uthsc.edu

Received date: Jun 28, 2016; Accepted date: June 29, 2016; Published date: June 30, 2016

Citation: Davenport AS. Guest Editorial: Breast Cancer Epigenetics in the Era of Precision Medicine. J Clin Epigenet. 2016, 2:2

\section{Editorial}

The Precision Medicine Initiative (PMI) was officially unveiled on January 20, 2015 by President Obama during his State of the Union address. This initiative will transform healthcare by providing health professionals with new and improved strategies to identify individuals at risk for diseases like breast cancer and to determine which treatments and therapies are best suited for the patient. The term "precision medicine" which most researchers often refer to as "personalized or individualized medicine" considers the approach that one-size-does-not-fit-all [1]. The phrase "onesize-does-not-fit-all" refers to a treatment or drug that may work well for some individuals but not for others. A nice example is the anti-estrogen breast cancer drug tamoxifen (TAM) which is used to prevent breast cancer in high-risk populations and to treat postmenopausal estrogen receptor (ER) - positive breast cancers [2,3]. Breast cancer is the most common cancer and one of the leading causes of cancer death among women [4]. Close to one-third of postmenopausal breast cancer patients experience a relapse after adjuvant treatment with TAM $[5,6]$. It is unclear as to why some patients experience a more favorable response to certain drugs, such as TAM, while other patients with the same diagnosis experience multiple adverse side effects from taking TAM. Recent advances in the field of breast cancer pharmacogenomics provide strong evidence that acquired or inherited genetic differences in drug metabolic pathways can affect an individual's response to TAM and other chemotherapeutic drugs [7-10]. In support of these observations, our pharmacogenetic study showed that a single nucleotide polymorphism in the promoter of the TAM metabolizing gene UDP-glucuronosyltransferase 1A4 (UGT1A4) significantly decreases how TAM and its derivatives are metabolized in the human liver [11]. These studies, along with countless other pharmacogenomic studies, demonstrate the influence of pharmacogenomics on policy implementation and efforts that guide the development of more effective medical treatments tailored to an individual's genetic makeup. Currently, more than 100 pharmacogenomic biomarkers have been added to drug labels that may help clinicians take appropriate actions to manage their patient's health based on their biomarker information [12]. Because the PMI has directed most of its efforts toward research that seeks to provide new knowledge about how an individual's genetic makeup, environment, and behavior can impact disease risk and response to treatment, I expect that this initiative will require continuous and effective collaborations between clinicians, scientists, health professionals and policy makers.

Personally, I envision that the field of breast cancer epigenetics will soon be at the forefront of the PMI, especially since breast cancer drugs and lifestyle behaviors can alter the methylome, the histone code, and microRNA (miRNA) expression in breast cells [13-16]. Unlike genetic variations which can alter the expression of a gene by changing its DNA sequence, the term "epigenetics" refers to non-heritable changes in the DNA that can alter gene expression [17]. Currently, more than 100 tumor suppressor genes are frequently hypermethylated in breast cancer and alter its gene expression [18-20]. We previously showed that AugustusCopenhagen Irish $(\mathrm{ACl})$ rats exposed to continuous 17Bestradiol for 6 weeks and 12 weeks, resulted in the appearance of the earliest preneoplastic morphological changes, and alteration of global DNA methylation, hypermethylation and silencing of the Rassfla gene, and increased histone modifications [21]. These results clearly demonstrate that epigenetic dysregulation is an underlying event in breast carcinogenesis. Even databases such as the Cancer Genome Atlas (TCGA) Network has catalogued aberrations in the epigenetic machinery of thousands of tumors relative to matched normal cellular genomes [22]. However, to my knowledge, epigenetic biomarkers have not been implemented in clinical practice for breast cancer screening and diagnosis. In conclusion, the potential for precision medicine to improve breast cancer care is great, and efforts from the PMI will bring us one step closer to transforming clinical practice. Only time will tell whether or not epigenetic tests and targeted therapies will become widely used for clinical diagnostics and precision medicine of breast cancer.

\section{References}

1. Snyderman R (2012) Personalized health care: from theory to practice. Biotechnol J 7: 973-979.

2. Sakorafas GH, Farley DR, Peros G (2008) Recent advances and current controversies in the management of DCIS of the breast. Cancer Treat Rev 34: 483-97.

3. Cuzick J, Sestak I, Pinder SE, Ellis IO, Forsyth S, et al. (2011) Effect of tamoxifen and radiotherapy in women with locally excised ductal carcinoma in situ: long-term results from the UK/ANZ DCIS trial. Lancet Oncol 12: 21-29. 
4. DeSantis CE, Fedewa SA, Goding Sauer A, Kramer JL, Smith RA, et al. (2016) Breast cancer statistics, 2015: Convergence of incidence rates between black and white women. CA Cancer J Clin 66: 31-42.

5. Nicholson RI, Gee JM, Knowlden J, McClelland R, Madden TA, et al. (2003) The biology of antihormone failure in breast cancer. Breast Cancer Res Treat 80: S29-S34.

6. Kurebayashi J (2003) Endocrine-resistant breast cancer: underlying mechanisms and strategies for overcoming resistance. Breast Cancer 10: 112-119.

7. Klotz $U$ (2007) The role of pharmacogenetics in the metabolism of antiepileptic drugs: pharmacokinetic and therapeutic implications. Clin Pharmacokinet 46: 271-279.

8. Roses $A D$ (2000) Pharmacogenetics and the practice of medicine. Nature 405: 857-865.

9. Hertz DL, Deal A, Ibrahim JG, Walko CM, Weck KE, et al. (2016) Tamoxifen Dose Escalation in Patients With Diminished CYP2D6 Activity Normalizes Endoxifen Concentrations Without Increasing Toxicity. Oncologist.

10. Lim JS, Sutiman N, Muerdter TE, Singh O, Cheung YB, et al (2016) Association of CYP2C19*2 and associated haplotypes with lower norendoxifen concentrations in tamoxifen-treated Asian breast cancer patients. Br J Clin Pharmacol 81: 1142-1152.

11. Greer AK, Dates $C R$, Starlard-Davenport A, Edavana VK, Bratton SM, et al. (2014) A potential role for human UDPglucuronosyltransferase $1 \mathrm{~A} 4$ promoter single nucleotide polymorphisms in the pharmacogenomics of tamoxifen and its derivatives. Drug Metab Dispos. 42: 1392-1400.

12. Sandoval J, Peiro-Chova L, Pallardo FV, Garcia-Gimenez JL (2013) Epigenetic biomarkers in laboratory diagnostics: emerging approaches and opportunities. Expert Rev Mol Diagn. 13: 457-471.

13. Stirzaker C, Zotenko E, Clark SJ (2016) Genome-wide DNA methylation profiling in triple-negative breast cancer reveals epigenetic signatures with important clinical value. Mol Cell Oncol 3: e1038424.

14. Stirzaker C, Zotenko E, Song JZ, Qu W, Nair SS, et al. (2015) Methylome sequencing in triple-negative breast cancer reveals distinct methylation clusters with prognostic value. Nat Commun. 6: 5899.

15. Roll JD, Rivenbark AG, Sandhu R, Parker JS, Jones WD, et al. (2013) Dysregulation of the epigenome in triple-negative breast cancers: basal-like and claudin-low breast cancers express aberrant DNA hypermethylation. Exp Mol Pathol 95: 276-287.

16. Ledford H (2008) Language: Disputed definitions. Nature 455: 1023-1028.

17. Holm K, Staaf J, Lauss M, Aine M, Lindgren D, et al. (2016) An integrated genomics analysis of epigenetic subtypes in human breast tumors links DNA methylation patterns to chromatin states in normal mammary cells. Breast Cancer Res 18: 27.

18. Bediaga NG, Acha-Sagredo A, Guerra I, Viguri A, Albaina C, et al. (2010) DNA methylation epigenotypes in breast cancer molecular subtypes. Breast Cancer Res 12: R77.

19. Feinberg AP, Tycko B (2004) The history of cancer epigenetics. Nat Rev Cancer 4: 143-153.

20. Starlard-Davenport A, Tryndyak VP, James SR, Karpf AR, Latendresse JR, et al. (2010) Mechanisms of epigenetic silencing of the Rassf1a gene during estrogen-induced breast carcinogenesis in ACl rats. Carcinogenesis 31: 376-381.

21. Gnad F, Doll S, Manning G, Arnott D, Zhang Z (2015) Bioinformatics analysis of thousands of TCGA tumors to determine the involvement of epigenetic regulators in human cancer. BMC Genomics 8: S5.

22. Tomczak K, Czerwinska P, Wiznerowicz M (2015) The Cancer Genome Atlas (TCGA): an immeasurable source of knowledge. Contemp Oncol (Pozn) 19: A68-A77. 